\title{
Rebar Impalement Injury Throughout Bilateral Hemithorax and Pericardium
}

\author{
Tevfik Ilker Akcam ${ }^{*}$, Ayse Gul Ergonul², Ali Ozdil², Alpaslan Cakan², Ufuk Cagırıcı ${ }^{2}$ \\ ${ }^{1}$ Dr. Suat Seren Chest Disease and Thoracic Surgery Training and Research Hospital, Department \\ of Thoracic Surgery, Izmir, Turkey \\ ${ }^{2}$ Ege Universıty, Faculty of Medıcıne, Department of Thoracıc Surgery, Izmir, Turkey \\ Email: ${ }^{*}$ tevfikilkerakcam@hotmail.com, mdaysegulcevik@yahoo.com, \\ alpaslan.cakan@ege.edu.tr, ufuk.cagirici@ege.edu.tr
}

Received 10 June 2015; accepted 16 August 2015; published 20 August 2015

Copyright @ 2015 by authors and Scientific Research Publishing Inc. This work is licensed under the Creative Commons Attribution International License (CC BY). http://creativecommons.org/licenses/by/4.0/

\section{Abstract}

Thoracic traumas have an important place among all injuries as they can cause significant mortality and morbidity. The thoracic injuries are the large part of trauma with head and extremity injuries. Thoracic traumas are divided into two groups, including penetrating and blunt. The primary causes for penetrating traumas are wounds caused by gunshot and sharp objects. The lungs are the most injured organ in penetrating thoracic traumas with many organ injuries accompanied. This case report is about a rebar impalement into bilateral hemitoraces and pericardium after falling down in spite of any injury is not occurred in heart, lung and great vessels. The fact that an injury to such an extent does not cause any intrathoracic catastrophic event is something that has not been reported in the past.

\section{Keywords}

Rebar, Injury, Hemithoraces, Pericardium

\section{Introduction}

Thoracic traumas have an important place among all injuries as they can cause significant mortality and morbidity. Penetrating injuries account for $20 \%-40 \%$ among all thoracic injuries [1]. The primary causes for these traumas are wounds caused by gunshot and stab objects [2]. In addition, impalement thoracic injury are very rare and rarely compatible with survive. So few cases have been reported in the literature [3]. Especially chance of survival decreases if accompanied mediastinal injury [4]. The bilateral penetrating thoracic and mediastinal case

${ }^{*}$ Corresponding author.

How to cite this paper: Akcam, T.I., Ergonul, A.G., Ozdil, A., Cakan, A. and Cagırıcı, U. (2015) Rebar Impalement Injury Throughout Bilateral Hemithorax and Pericardium. Open Journal of Thoracic Surgery, 5, 31-34.

http://dx.doi.org/10.4236/ojts.2015.53007 
reported in this case report, which occurred from a rebar (iron bar) and did not cause intrathoracic organ injury, has never been encountered in the literature. The fact that an injury to such an extent does not cause any intrathoracic catastrophic event is something that has not been reported in the past.

\section{Case}

A 42-year-old male patient, who was admitted to the hospital due to a penetration trauma caused by a fall into a rebar in the side of the patient's chest while working on a staircase, was seen at the emergency service. It was found that the spiral rebar, which had a length of $60 \mathrm{~cm}$ and a thickness of $8 \mathrm{~mm}$, penetrated one of the patient's hemithorax and exited through the other. One end of the construction rebar that transversely passed through the thorax was at the intersection of the left hemithorax anterior axillary line with the eighth intercostal space, and the other end was at the intersection of the right hemithorax anterior axillary line with the seventh intercostal space (Figure 1). Patient's blood pressure was of 90/55 mmHg, the pulse was tachycardia of 120 - 130 beats/minutes, oxygen saturation was $92 \%$ on room air, awareness was confi. There was no communication with patient. FAST (focused assessment with sonography for trauma) ultrasound was performed on near stretcher. Pericardial effusion, pleural effusion and possibility of splenic laceration were reported in first assessment. So patient was considered non-stabil. The decision was made to perform an operation without delay for further radiological examinations. Patient underwent emergency operation with these findings.

Considering the lower hemithorax injury and the possible splenic laceration, laparotomy and thoracotomy with a clamshell incision (bilateral anterior thoracotomy and transverse sternotomy) were performed simultaneously with the general surgery team. The laparotomy showed that there were no intrabdominal organ injuries and the hemidiaphragms were intact. The thoracotomy performed with a clamshell incision, which would allow the exploration of both hemithoraces and pericardial region concomitantly (Figure 2), showed that the tion rebar penetrated the pericardial cavity. No injury was found in either lung, the heart, or major vessels in the exploration. The foreign body was removed in a controlled manner and the surgical procedure was completed. The patient was problem-free in the postoperative period and there was no complication. Thorax and mediastinal tube were ended postoperative 2 and 3 days. Patient discharged on day 4; no problems were found in the followup at the polyclinic.

\section{Discussion}

The thoracic injuries are the third most common injuries among all injuries, after head and extremity [5]. Penetrating thoracic traumas are less frequently observed compared to blunt traumas. Thirty-seven percent of all thoracic traumas occurs due to stab wounds, whereas only 5\% occurs by gunshot injuries [2].

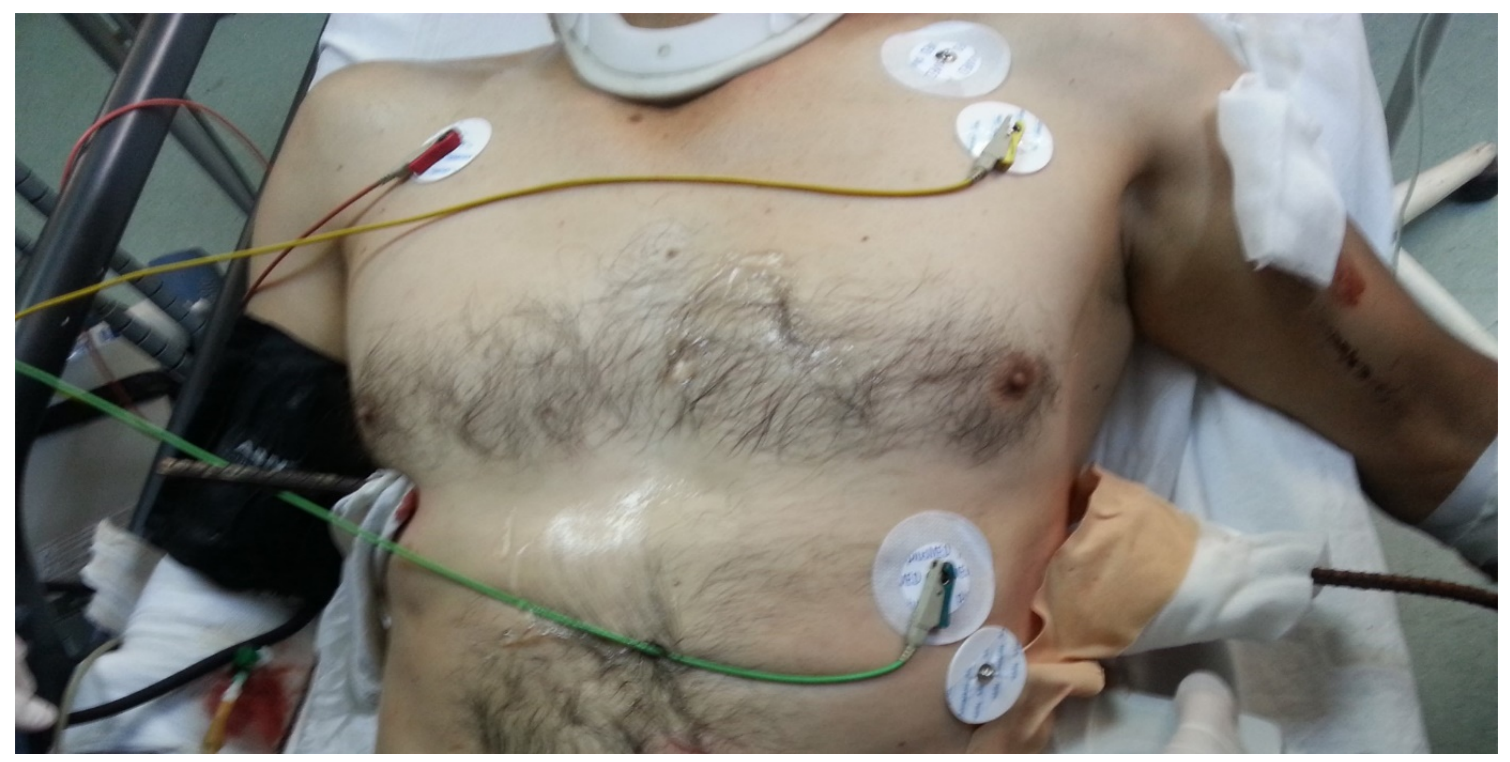

Figure 1. Preoperative wiew. 


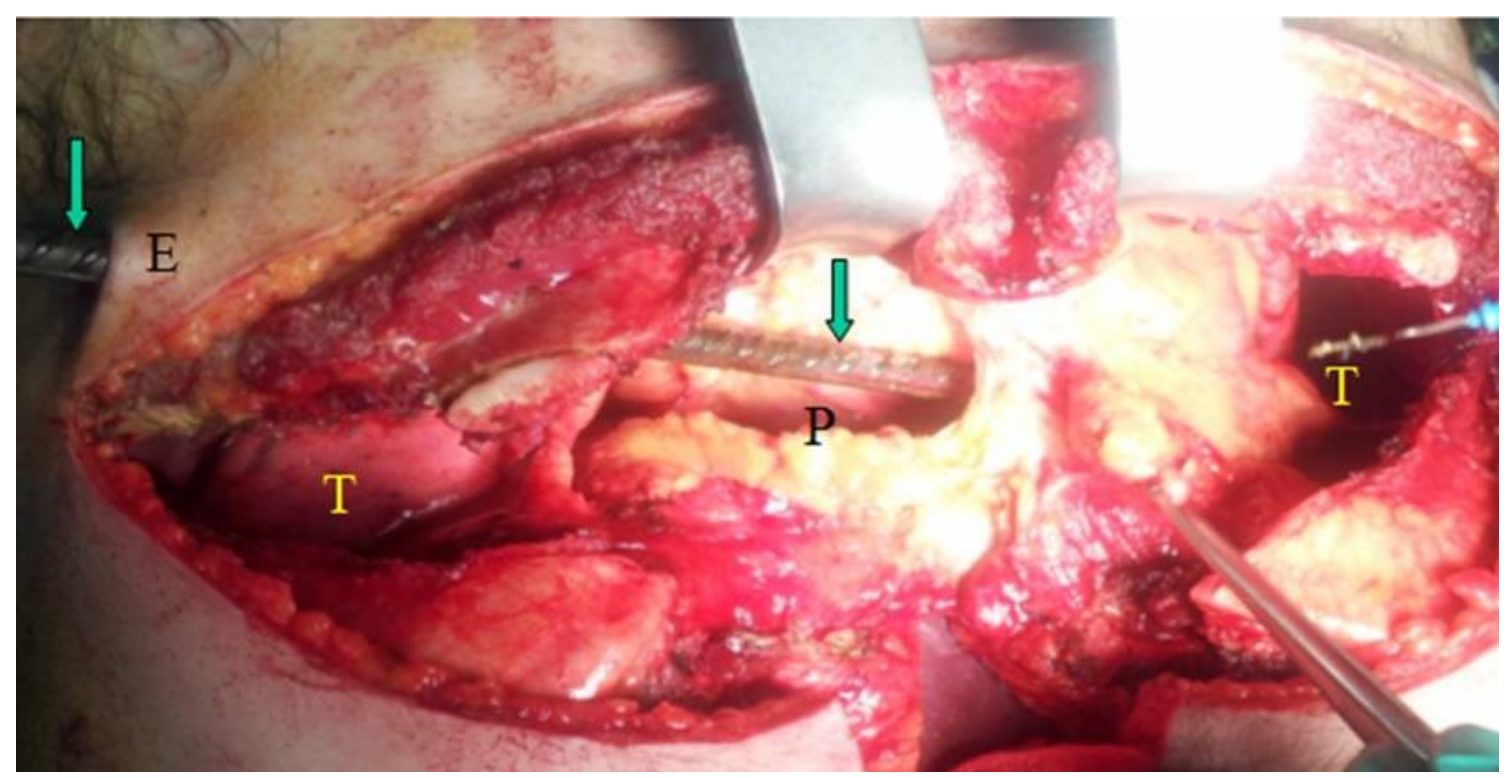

Figure 2. Peroperative wiew (E: Exit; T: Thoracic cavities; P: Pericardial cavity).

Impalement thoracic injuries are usually mortal therefore few cases have been reported in the literature. These injuries are occurred unilateral generally [6]. No study is found in the type of throughout bilateral thorax and mediastinum in the literature. The lungs are the most injured organ in penetrating thoracic traumas. Pneumothorax and/or hemothorax are frequently observed as a result of pulmonary parenchymal injury [2]. These injuries may be accompanied by mediastinum, and heart and major vessel injuries [7]. The incision type to be used for the surgical approach may vary depending on the concomitant injury. For injuries passing through the mediastinum, the approach with median sternotomy or transverse sternotomy is a proper choice [2] [8].

The incision which is most frequently used in penetrating thoracic injuries and allows for ease of intervention to the pulmonary hilum is the posterolateral thoracotomy approach. However, other incisions may also be required. The approach used in the emergency thoracotomy is the anterior thoracotomy [9]; however, median sternotomy or transverse sternotomy may also be performed. In cases of heart and major vessel injuries accompanied by tracheobronchial injuries and in cases of bilateral injuries, the approach with a clamshell incision is recommended [10]. As the penetrating body passes through both hemothoraces in the case reported, the decision was made to perform a bilateral thoracotomy with a clamshell incision that would allow the exploration of all these regions.

Although the type of trauma and the cause of trauma seem frightening, severe intrathoracic organ injuries are rarely observed. In the present case, it may be concluded that it is a huge coincidence that an injury to such extent does not cause mortal injury to the patient.

\section{References}

[1] Cakan, A., Yuncu, G., Olgac, G., Timucin, A., Sevinc, S., Kaya, S.O., et al. (2001) Thoracic Trauma: Analysis of 987 patients. Turkish Journal of Trauma \& Emergency Surgery, 7, 236-241.

[2] Guitron, J., Huffman, L.C., Howington, J.A. and Locicero, J. (2010) Blunt and Penetrating İnjuries of the Chest Wall, Pleura and Lungs. In: Shilds, T.W., Locicero, J., Reed, C.E., Fein, R.H., Eds., General Thoracic Surgery, Lippincott Williams and Wilkins, Philadelphia, 891-902.

[3] Ruano, R.M., Pereira, B.M., Biazzoto, G., Bortoto, J.B., and Fraga, G.P. (2014) Management of Severe Thoracic İmpalement Trauma against Two-Wheeled Horse Carriage: A Case Report and Literature Review. Indian Journal of Surgery, 76, 297-302. http://dx.doi.org/10.1007/s12262-013-0825-4

[4] Tsuei, M.K., Riley, R.D., Oaks, T.E. and Chang, M.C. (2001) Mediastinal Impalement with Survival: A Case Report. The American Surgeon, 67, 594-596.

[5] Basoglu, A., Akdag, A.O., Celik, B. and Demircan, S. (2004) Thoracic Trauma: An Analysis of 521 Patients. Turkish Journal of Trauma \& Emergency Surgery, 10, 42-46. 
[6] Edwin, F., Tettey, M., Sereboe, L., Aniteye, E., Kotei, D., Tamatey, M., et al. (2009) Impalement Injuries of the Chest. Ghana Medical Journal, 43, 86-89.

[7] Onat, S., Ulku, R., Avci, A., Ateş, G. and Ozcelik, C. (2011) Urgent Thoracotomy for Penetrating Chest Trauma: Analysis of 158 Patients of a Single Center. Injury, 42, 900-904. http://dx.doi.org/10.1016/j.injury.2010.02.004

[8] Inci, I., Özçelik, C., Taçyildiz, I., Nizam, O., Eren, N. and Özgen, G. (1998) Penetrating Chest Injuries: Unusually High Incidence of High-Velocity Gunshot Wounds in Civilian Practice. World Journal of Surgery, 22, 438-442. http://dx.doi.org/10.1007/s002689900412

[9] Akcam, T.I., Turhan, K., Ergonul, A.G., Oguz, E., Cakan, A. and Cagırıcı, U. (2012) A Life-Saving Approach after Thoracic Trauma: Emergency Room Thoracotomy. Turkish Journal of Trauma \& Emergency Surgery, 18, 306-310. http://dx.doi.org/10.5505/tjtes.2012.70194

[10] Riyad, K.J. and Douglas, E.W. (2007) Traumatic Injury of the Trachea and Bronchus. Thoracic Surgery Clinics, 17, 35-46. http://dx.doi.org/10.1016/j.thorsurg.2007.03.005 